\title{
Internet Addiction and Internet Gaming Disorder and Associated Insomnia among a Sample of Al-Azhar University Students, Clinical Study
}

\author{
Mohamed Abdel Fattah Soliman Al Gammal, Mohamed Mohamed Ali Elsheikh, Abdelrahman \\ Ahmed Elrefaey Abozahra
}

\author{
Department of Psychiatry, Faculty of Medicine, Al-Azhar University, Cairo, Egypt
}

Corresponding author: Abdelrahman Ahmed Elrefaey Abozahra,

E-mail: abdelrahmanabozahra19@gmail.com, Mobile: (+20)01120029140

\begin{abstract}
Objective: The aim of this cross-sectional study was to examine and compare the prevalence of internet addiction and internet gaming disorder with examination of related sleep problems. Also identifying risk factors associated with them .

Patients and methods: Data were collected from 60 students of Al-Azhar University. From randomly selected 6 different faculties. We found a high prevalence rate of Internet Addiction (IA) among them. This prevalence was higher than Internet Gaming Disorder (IGD) prevalence. Both of IA and IGD are inversely correlated to sleep quality. Theoretical faculties are at higher risk for IA and IGD.

Middle Socioeconomic status (SES) of adolescents' parents is related to IA but not related to IGD. The study was approved by the medical ethics committee of Al-Azhar University Hospitals and a written informed consent was obtained from all patients.
\end{abstract}

Results: According to the results of the Internet Addiction Test (IAT), 46.7\% of the sample had moderate internet addiction, $3.3 \%$ had severe internet addiction and $40 \%$ had mild internet addiction. According to results of (IGD) Scale 50\% were at risk to develop Internet Gaming Disorder (IGD)\&13.6\% were disordered. According to Pittsburgh Sleep Quality Index (PSQI), (60\%) of the participants were suffering from poor sleep Quality.

Conclusion: The current study has revealed a high prevalence rate of Internet Addiction (IA) among Al-Azhar university students. This prevalence was higher than Internet Gaming Disorder (IGD) prevalence. Both of IA and IGD are inversely correlated to sleep quality.

Keywords: IAT, IGD, PSQI, DSM-5.

\section{INTRODUCTION}

Internet addiction is a global phenomenon that has been a topic of increasing interest to clinicians, researchers and stakeholders such as teachers, parents and community groups. Clinical research on behavioral addictions investigated many models of addiction: compulsive gambling, overeating, and compulsive sexual behavior. Similar addiction models have been applied to technological overuse $^{(\mathbf{1})}$.

Generally speaking, IA has been characterized by excessive or poorly controlled preoccupation, urges, and/or behaviors regarding internet use that lead to impairment or distress in several life domains ${ }^{(2)}$.

In contemporary society approximately $40 \%$ of the world population is online. Furthermore, global internet usage has grown nearly six-fold over the last decade ${ }^{(3)}$. The percentage of internet users in Egypt was $21.6 \%$ in 2010, which became $37.82 \%$ in 2015 (around 35 million users) ${ }^{(4)}$. Beard recommends diagnostic criteria of Internet Addiction. Five criteria are needed for diagnosis between pre-occupation, loss of control, negative mood if kept offline and negative consequences from pathological internet usage ${ }^{(5)}$.

Internet gaming is one of the most popular internet activities. It can be pleasurable and rewarding but some individuals develop pathological manner of usage of such activity. Through the past few years, researchers' interest towards this pathological behavior increased and Internet Gaming Disorder (IGD) was listed in Diagnostic and Statistical Manual 
of Mental Disorders (DSM-5). As mentioned in DSM-5, IGD is persistent and recurrent use of the internet to engage in games, often with other players, leading to clinically significant impairment or distress ${ }^{(6)}$.

No doubt that the internet became an integral part of our life. Also sleep maintains our homeostatic function. We need both of them but how they could affect each other is one of the important issues that recent studies started to demonstrate. Excessive internet use leads to irregular sleep patterns due to an irregular bedtime schedule, and this could lead to disturbed circadian rhythm (7). Some researchers found that not only internet addiction may affect sleep but also people who suffer from decreased ability to fall asleep at night, would engage in internet usage more than others keeping them at higher risk of internet $\operatorname{addiction}^{(7)}$

\section{AIM OF THE WORK}

The aim of this study was to:

1.Comare the Prevalence of internet addiction $\&$ internet gaming disorder among the selected population.

2.Assess essential risk factors (sex, socioeconomic class, role of theoretical \& practical faculties) of both internet addiction and internet gaming disorder.

3.Explore the associated insomnia among the pathological users.

4.Measure its impact on the academic achievement

\section{Patients and Methods:}

This cross-sectional study applied during the academic year 2018-2019 in Al-Azhar University, 200 questionnaires were randomly distributed to 200 students from 6 faculties of Al-Azhar University students (Commerce, Education, Shariaa, Medicine, Science, and Engineering). Due to the lack of cooperation of some students the number of questionnaires collected was 160, 40 questionnaires were excluded for incomplete data filling, then 60 questionnaires were excluded because of presence of psychiatric symptoms by SCID1.

Assessment and statistics were conducted on 60 students. The range of their age was $18-26$ years with mean of $21.9 \pm 2.7$, and $53.3 \%$ of the sample were females and $46.7 \%$ were males.
The assessment made by informative designed questionnaire ${ }^{(8)}$, SCID1, (SES) Scale, (IAT) ${ }^{(9)}$, (IGD) Scale ${ }^{(10)}$, (PSQI) ${ }^{(11)}$.

\section{Ethical and approval considerations:}

Oral and written consents were taken from the students taking into considerations maintaining the confidentiality of the data. In addition, approval of the Ethical Committee of Psychiatry Department, Al-Azhar University also was taken to do the research.

\section{Inclusion Criteria:}

- Being a student of Al-Azhar University.

- Age range: 18 - 26 years old.

- Both sexes.

\section{Exclusion Criteria:}

-Students who have psychiatric symptoms by SCID1 or receiving psychiatric medications.

\section{Statistical analysis:}

Recorded data were analyzed using the statistical package for social sciences, version 20.0 (SPSS Inc., Chicago, Illinois, USA). Quantitative data were expressed as mean \pm standard deviation (SD). Qualitative data were expressed as frequency and percentage.

\section{The following tests were done:}

- Independent-samples t-test of significance was used when comparing between two means.

- Chi-square $\left(\mathrm{x}^{2}\right)$ test of significance was used in order to compare proportions between two qualitative parameters.

- The confidence interval was set to $95 \%$ and the margin of error accepted was set to $5 \%$. The p-value was considered significant as the following:

- Probability (P-value)

- P-value <0.05 was considered significant.

- P-value <0.001 was considered as highly significant.

- P-value >0.05 was considered insignificant. 


\section{RESULTS}

Table (1): Personal characteristics of the sample.

\begin{tabular}{|c|c|c|c|}
\hline & & $\mathbf{N}$ & $\%$ \\
\hline \multicolumn{2}{|c|}{ Age (Yr) } & \multicolumn{2}{|c|}{$21.9 \pm 2.7$} \\
\hline $\operatorname{Sex}(n \%)$ & Males & 28 & $46.7 \%$ \\
\hline & Females & 32 & $53.3 \%$ \\
\hline \multirow[t]{3}{*}{ SES (n \%) } & Low & 3 & $5 \%$ \\
\hline & Middle & 36 & $60 \%$ \\
\hline & High & 21 & $35 \%$ \\
\hline \multirow[t]{6}{*}{ Faculty (n \%) } & Commerce & 11 & $18.3 \%$ \\
\hline & Shariaa & 10 & $16.7 \%$ \\
\hline & Education & 10 & $16.7 \%$ \\
\hline & Medicine & 10 & $16.7 \%$ \\
\hline & Science & 10 & $16.7 \%$ \\
\hline & Engineering & 9 & $15 \%$ \\
\hline Grades of the past & Excellent & 5 & $8.3 \%$ \\
\hline \multirow[t]{4}{*}{ year } & V. Good & 14 & $23.3 \%$ \\
\hline & Good & 22 & $36.6 \%$ \\
\hline & Accepted & 14 & $23.3 \%$ \\
\hline & Failed & 5 & $8.3 \%$ \\
\hline
\end{tabular}

Our sample consisted of 60 students of Al-Azhar University. The range of their age was 18-26 years with mean of $21.9 \pm 2.7$, and $53.3 \%$ of the sample was females and $46.7 \%$ were males. Most of the sample was of middle socioeconomic level (60\%). Data was collected from 6 different faculties. Grades of the students were divided into Excellent, Very Good, Good, Accepted, Failed. All of those characteristics are displayed in Table (1).

Table (2): Prevalence of internet addiction among selected sample, and the most visited sites:

\begin{tabular}{|c|c|c|c|}
\hline & & $\mathbf{N}$ & $\%$ \\
\hline \multirow{4}{*}{$\begin{array}{c}\text { Internet Addiction } \\
\text { (n \%) }\end{array}$} & Normal & 6 & $10 \%$ \\
\hline & Mild & 24 & $40 \%$ \\
\hline & Moderate & 28 & $46.7 \%$ \\
\hline & Severe & 2 & $3.3 \%$ \\
\hline \multirow{4}{*}{$\begin{array}{l}\text { Most visited site } \\
(\mathrm{n} \%)\end{array}$} & Social Media & 53 & $88.3 \%$ \\
\hline & Information Surfing & 4 & $6.7 \%$ \\
\hline & Internet Gaming & 2 & $3.3 \%$ \\
\hline & Pornographic Sites & 1 & $1.7 \%$ \\
\hline Hrs. online/day & & \multicolumn{2}{|c|}{$5.7 \pm 1.9$} \\
\hline
\end{tabular}

Students used the internet for about $5.7 \pm 1.9$ hours/day and most of them using it for more than 1 year. According to the results of the Internet Addiction Test (IAT), 46.7\% of the sample had moderate internet addiction. Through asking the students about the most visited sites we found that $88.3 \%$ from them were using the social media. 
Table (3): Online gaming behavior

\begin{tabular}{|c|c|c|c|}
\hline & & $\mathbf{N}$ & $\%$ \\
\hline \multirow[t]{2}{*}{ Playing online Games } & No & 38 & $63.3 \%$ \\
\hline & Yes & 22 & $36.7 \%$ \\
\hline \multirow[t]{2}{*}{ Type of online Games } & MMO & 10 & $45.5 \%$ \\
\hline & Not MMO & 12 & $54.5 \%$ \\
\hline \multirow[t]{3}{*}{ Internet Gaming Disorder (Among players only) } & Normal & 8 & $36.4 \%$ \\
\hline & Risky & 11 & $50 \%$ \\
\hline & Disordered & 3 & $13.6 \%$ \\
\hline
\end{tabular}

Results showed that $63.3 \%$ from the students were not using online games. Among the rest of the sample $50 \%$ were at risk to develop Internet Gaming Disorder (IGD). Also, we found that $45.5 \%$ from game players use Massive Multiplayer Online (MMO) games.

According to Pittsburgh Sleep Quality Index (PSQI), 36 persons (60\%) of the participants were suffering from poor sleep Quality.

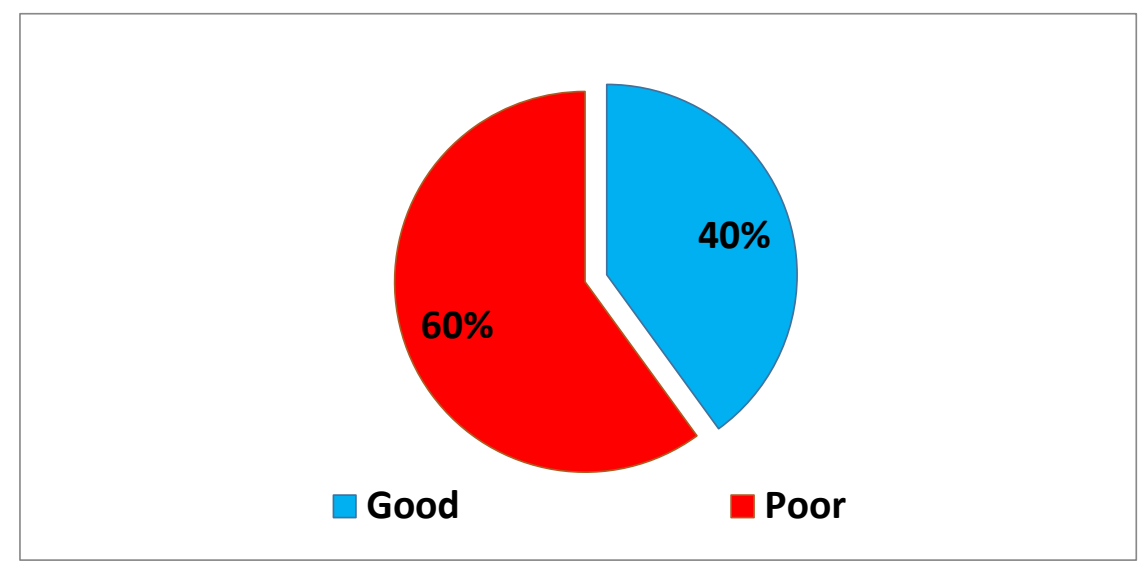

Fig. (1): Sleep Quality of the students

\section{Essential relations:}

Table (4): Relation between internet addiction and personal characteristics

\begin{tabular}{|c|c|c|c|c|c|c|c|c|c|c|c|}
\hline & \multicolumn{8}{|c|}{ Internet Addiction } & \multirow{3}{*}{$\mathbf{P}$} & \multirow{3}{*}{ Sig } \\
\hline & & \multicolumn{2}{|c|}{$\begin{array}{c}\text { Normal } \\
(\mathrm{n}=6)\end{array}$} & \multicolumn{2}{|c|}{$\begin{array}{c}\text { Mild } \\
(n=24)\end{array}$} & \multicolumn{2}{|c|}{$\begin{array}{c}\text { Moderate } \\
(n=28)\end{array}$} & \multicolumn{2}{|c|}{$\begin{array}{l}\text { Severe } \\
(n=2)\end{array}$} & & \\
\hline & & $\mathbf{N}$ & $\%$ & $\mathbf{N}$ & $\%$ & $\mathbf{N}$ & $\%$ & $\mathbf{N}$ & $\%$ & & \\
\hline \multirow[t]{2}{*}{ Sex } & Males & 4 & $66.7 \%$ & 15 & $62.5 \%$ & 16 & $57.1 \%$ & 1 & $50 \%$ & \multirow[t]{2}{*}{0.94} & \multirow[t]{2}{*}{$\overline{N S}$} \\
\hline & Females & 2 & $33.3 \%$ & 9 & $37.5 \%$ & 12 & $42.9 \%$ & 1 & $50 \%$ & & \\
\hline \multirow[t]{6}{*}{ Faculty } & Commerce & 1 & $16.7 \%$ & 4 & $16.7 \%$ & 0 & $0 \%$ & 2 & $100 \%$ & \multirow[t]{6}{*}{$<0.001$} & \multirow[t]{6}{*}{ HS } \\
\hline & Shariaa & 1 & $16.7 \%$ & 9 & $37.5 \%$ & 0 & $0 \%$ & 0 & $0 \%$ & & \\
\hline & Education & 2 & $33.3 \%$ & 3 & $12.5 \%$ & 18 & $64.3 \%$ & 0 & $0 \%$ & & \\
\hline & Medicine & 1 & $16.7 \%$ & 3 & $12.5 \%$ & 10 & $35.7 \%$ & 0 & $0 \%$ & & \\
\hline & Science & 1 & $16.7 \%$ & 2 & $8.3 \%$ & 0 & $0 \%$ & 0 & $0 \%$ & & \\
\hline & Engineering & 0 & $0 \%$ & 2 & $8.3 \%$ & 0 & $0 \%$ & 0 & $0 \%$ & & \\
\hline \multirow{6}{*}{$\begin{array}{c}\text { Grades } \\
\text { Of the } \\
\text { past } \\
\text { year }\end{array}$} & A & 1 & $16.7 \%$ & 3 & $12.5 \%$ & 2 & $7.1 \%$ & 1 & $50 \%$ & \multirow[t]{5}{*}{0.0002} & \multirow[t]{5}{*}{ HS } \\
\hline & B & 2 & $33.3 \%$ & 7 & $29.2 \%$ & 6 & $21.4 \%$ & 0 & $0 \%$ & & \\
\hline & $\mathrm{C}$ & 3 & $50 \%$ & 9 & $37.5 \%$ & 10 & $35.7 \%$ & 0 & $0 \%$ & & \\
\hline & $\mathrm{D}$ & 1 & $16.7 \%$ & 5 & $20.8 \%$ & 10 & $35.7 \%$ & 0 & $0 \%$ & & \\
\hline & $\mathrm{F}$ & 0 & $0 \%$ & 0 & $0 \%$ & 0 & $0 \%$ & 1 & $50 \%$ & & \\
\hline & Low & 3 & $50 \%$ & 2 & $8.3 \%$ & 1 & $3.6 \%$ & 0 & $0 \%$ & & \\
\hline
\end{tabular}




\begin{tabular}{|c|c|c|c|c|c|c|c|c|c|c|c|}
\hline \multirow{2}{*}{ SES } & Middle & 3 & $50 \%$ & 13 & $54.2 \%$ & 18 & $64.3 \%$ & 0 & $0 \%$ & 0.008 & \multirow{2}{*}{ S } \\
\cline { 2 - 7 } & High & 0 & $0 \%$ & 9 & $37.5 \%$ & 9 & $32.1 \%$ & 2 & $100 \%$ & & \\
\hline
\end{tabular}

Table (5): Relation between internet addiction and sleep quality.

\begin{tabular}{|c|c|c|c|c|c|c|c|c|c|c|c|}
\hline & \multicolumn{8}{|c|}{ Internet Addiction } & \multirow{3}{*}{$\mathbf{P}$} & \multirow{3}{*}{ Sig } \\
\hline & & \multicolumn{2}{|c|}{$\begin{array}{c}\text { Normal } \\
(n=6)\end{array}$} & \multicolumn{2}{|c|}{$\begin{array}{c}\text { Mild } \\
(n=24)\end{array}$} & \multicolumn{2}{|c|}{$\begin{array}{c}\text { Moderate } \\
(\mathbf{n}=\mathbf{2 8})\end{array}$} & \multicolumn{2}{|c|}{$\begin{array}{l}\text { Severe } \\
(n=2)\end{array}$} & & \\
\hline & & $\mathbf{N}$ & $\%$ & $\mathbf{N}$ & $\%$ & $\mathbf{N}$ & $\%$ & $\mathbf{N}$ & $\%$ & & \\
\hline \multirow[t]{2}{*}{ Sleep } & Poor & 1 & $16.7 \%$ & 1 & $4.2 \%$ & 8 & $28.6 \%$ & 2 & $100 \%$ & \multirow[t]{2}{*}{0.004} & \multirow[t]{2}{*}{$\mathbf{S}$} \\
\hline & Good & 5 & $83.3 \%$ & 23 & $95.8 \%$ & 20 & $71.4 \%$ & 0 & $0 \%$ & & \\
\hline
\end{tabular}

$$
\mathrm{S} \text { : significant }
$$

This table shows statistically significant ( $\mathrm{p}$-value $<0.05$ ) correlation between sleep quality and internet addiction.

Table (6): Relation between internet gaming disorder (IGD) and personal characteristics

\begin{tabular}{|c|c|c|c|c|c|c|c|c|c|}
\hline & \multicolumn{6}{|c|}{ Internet Gaming Disorder } & \multirow{3}{*}{$\mathbf{P}$} & \multirow{3}{*}{ Sig } \\
\hline & & \multicolumn{2}{|c|}{$\begin{array}{l}\text { Normal } \\
(\mathrm{n}=8)\end{array}$} & \multicolumn{2}{|c|}{$\begin{array}{c}\text { Risky } \\
(n=11)\end{array}$} & \multicolumn{2}{|c|}{$\begin{array}{c}\text { Disordered } \\
(n=3)\end{array}$} & & \\
\hline & & $\mathbf{N}$ & $\%$ & $\mathbf{N}$ & $\%$ & $\mathbf{N}$ & $\%$ & & \\
\hline \multirow[t]{2}{*}{ Sex } & Male & 5 & $62.5 \%$ & 7 & $63.6 \%$ & 2 & $66.7 \%$ & \multirow{2}{*}{0.99} & \multirow{2}{*}{ NS } \\
\hline & Female & 3 & $37.5 \%$ & 4 & $36.4 \%$ & 1 & $33.3 \%$ & & \\
\hline \multirow[t]{6}{*}{ Faculty } & Commerce & 0 & $0 \%$ & 1 & $9.1 \%$ & 2 & $66.7 \%$ & \multirow{6}{*}{0.021} & \multirow{6}{*}{$\mathbf{S}$} \\
\hline & Shariaa & 0 & $0 \%$ & 2 & $18.2 \%$ & 0 & $0 \%$ & & \\
\hline & Education & 0 & $0 \%$ & 2 & $18.2 \%$ & 0 & $0 \%$ & & \\
\hline & Medicine & 2 & $25 \%$ & 4 & $36.4 \%$ & 1 & $33.3 \%$ & & \\
\hline & Science & 1 & $12.5 \%$ & 2 & $18.2 \%$ & 0 & $0 \%$ & & \\
\hline & Engineering & 5 & $62.5 \%$ & 0 & $0 \%$ & 0 & $0 \%$ & & \\
\hline \multirow{5}{*}{$\begin{array}{c}\text { Grades } \\
\text { Of the } \\
\text { past } \\
\text { year }\end{array}$} & A & 1 & $12.5 \%$ & 1 & $9.1 \%$ & 1 & $33.3 \%$ & \multirow{5}{*}{0.88} & \multirow{5}{*}{ NS } \\
\hline & B & 1 & $12.5 \%$ & 3 & $27.3 \%$ & 0 & $0.0 \%$ & & \\
\hline & $\mathrm{C}$ & 2 & $25.0 \%$ & 1 & $9.1 \%$ & 1 & $33.3 \%$ & & \\
\hline & $\mathrm{D}$ & 1 & $12.5 \%$ & 3 & $27.3 \%$ & 0 & $0.0 \%$ & & \\
\hline & $\mathrm{F}$ & 2 & $25.0 \%$ & 2 & $18.2 \%$ & 1 & $33.3 \%$ & & \\
\hline \multirow[t]{3}{*}{ SES } & Low & 2 & $25.0 \%$ & 3 & $27.3 \%$ & 1 & $33.3 \%$ & \multirow{3}{*}{0.98} & \multirow{3}{*}{ NS } \\
\hline & Middle & 3 & $37.5 \%$ & 5 & $45.5 \%$ & 1 & $33.3 \%$ & & \\
\hline & High & 3 & $37.5 \%$ & 3 & $27.3 \%$ & 1 & $33.3 \%$ & & \\
\hline
\end{tabular}

NS: not significant S: significant HS: highly significant

This table shows: No statistically significant ( $\mathrm{p}$-value $>0.05$ ) correlation between (Sex and internet gaming disorder), (grades and internet gaming disorders) and (SES and internet gaming disorder). Statistically significant ( $\mathrm{p}$-value $<0.05$ ) correlation between faculty and internet gaming disorder.

Table (7): Relation between internet gaming disorder and sleep quality.

\begin{tabular}{|c|c|c|c|c|c|c|c|c|c|}
\hline & \multicolumn{6}{|c|}{ Internet Gaming Disorder } & \multirow{3}{*}{$\mathbf{P}$} & \multirow{3}{*}{ Sig } \\
\hline & & \multicolumn{2}{|c|}{$\begin{array}{l}\text { Normal } \\
(n=8)\end{array}$} & \multicolumn{2}{|c|}{$\begin{array}{l}\text { Risky } \\
(\mathbf{n}=11)\end{array}$} & \multicolumn{2}{|c|}{$\begin{array}{l}\text { Disordered } \\
(\mathbf{n}=\mathbf{3})\end{array}$} & & \\
\hline & & $\mathbf{N}$ & $\%$ & $\mathbf{N}$ & $\%$ & $\mathbf{N}$ & $\%$ & & \\
\hline \multirow[t]{2}{*}{ Sleep } & Poor & 6 & $75 \%$ & 9 & $81.8 \%$ & 0 & $0 \%$ & \multirow{2}{*}{0.039} & \multirow{2}{*}{ S } \\
\hline & Good & 2 & $25 \%$ & 3 & $27.3 \%$ & 3 & $100 \%$ & & \\
\hline
\end{tabular}

S: significant 
This table shows statistically significant $(\mathrm{p}$-value $<0.05)$ correlation between sleep quality and internet gaming disorder.

Table 8: Relation between internet addiction and internet gaming disorder.

\begin{tabular}{|c|c|c|c|c|c|c|c|c|c|c|c|}
\hline & \multicolumn{8}{|c|}{ Internet Addiction } & \multirow{3}{*}{$\mathbf{P}$} & \multirow{3}{*}{ Sig } \\
\hline & & \multicolumn{2}{|c|}{$\begin{array}{c}\text { Normal } \\
(n=6)\end{array}$} & \multicolumn{2}{|c|}{$\begin{array}{c}\text { Mild } \\
(n=24)\end{array}$} & \multicolumn{2}{|c|}{$\begin{array}{l}\text { Moderate } \\
(\mathrm{n}=28)\end{array}$} & \multicolumn{2}{|c|}{$\begin{array}{l}\text { Severe } \\
(n=2)\end{array}$} & & \\
\hline & & $\mathbf{N}$ & $\%$ & $\mathbf{N}$ & $\%$ & $\mathbf{N}$ & $\%$ & $\mathbf{N}$ & $\%$ & & \\
\hline \multirow{3}{*}{$\begin{array}{l}\text { Internet } \\
\text { Gaming } \\
\text { Disorder }\end{array}$} & Normal & 4 & $66.7 \%$ & 10 & $41.7 \%$ & 8 & $28.6 \%$ & 0 & $0 \%$ & \multirow[t]{3}{*}{0.015} & \multirow[t]{3}{*}{$\mathrm{S}$} \\
\hline & Risky & 2 & $33.3 \%$ & 12 & $50 \%$ & 15 & $53.6 \%$ & 0 & $0 \%$ & & \\
\hline & Disordered & 0 & $.0 \%$ & 2 & $8.3 \%$ & 5 & $17.9 \%$ & 2 & $100 \%$ & & \\
\hline
\end{tabular}

S: significant

This table shows statistically significant ( $\mathrm{p}$-value $<0.05)$ correlation between internet addiction and internet gaming disorder.

\section{DISCUSSION}

This work is a cross sectional study in Al-Azhar University on 60 of the university students (age range 18-26 year), It was found that $91 \%$ from the selected sample suffer from internet addiction symptoms with different grades (mild, moderate and severe addiction) according to Internet Addiction Test ${ }^{(\mathbf{1 2})}$.

Such a high result agreed with previous researches that showed a higher risk of Internet Addiction among adolescents (13) specially university students because of lack of monitoring and presence of more free time ${ }^{(14)}$.

Most of the students in this research, about $89 \%$ of them, selected social media as the most visited sites. A study in Tanta University reported that $93 \%$ of students were using Facebook ${ }^{(15)}$. The higher they feel gratified while using social networks the more likely they report Internet Addiction symptoms ${ }^{(16)}$.

Nowadays, social networks sites e.g. Facebook can be easily accessed by smart phones and free applications WU et al. ${ }^{(17)}$ which increase the risk of Internet Addiction.

As regards severe Internet Addiction, in the current study, we found that $25 \%$ of pornographic sites users are severely addicted compared by $4 \%$ of social media users and $0 \%$ of other sites' users who exhibited milder form of Internet Addiction this may related to cross cultural differences.

Another popular internet activity is internet games. Only 36\% from our sample were using on-line games and $48 \%$ from gamers (about $18 \%$ from the whole sample) were at risk to develop Internet Gaming Disorder (IGD) while $16 \%$ of gamers were disordered (about $6 \%$ of the whole sample). In other studies, we could notice different prevalence rates this may be related to cross cultural differences and the use of different criteria and tools for diagnosis.

One of the aims of the current study was to test some factors that may influence internet usage e.g. socioeconomic status (SES), gender and type of faculty (theoretical or practical).We randomly selected 3 practical faculties (Medicine, Engineering and Science) and 3 theoretical faculties (Shariaa, Education and Commerce) and found a high significant relation between faculties and internet behavior. For example, in faculty of Education $66 \%$ from participants were at risk to develop IGD in comparison to $63 \%$ of engineering students were normal gamers. Also, regarding Internet addiction $62 \%$ of participants from faculty of Shariaa were moderate internet addicts but only $36 \%$ from faculty of medicine were moderate addicts. It could be because of more free time available to students of 
theoretical faculties that expose them to higher risk of IA and IGD ${ }^{(16)}$.

In our study, about $45 \%$ of participants were males and 55\% were females and no significant correlation was found between both genders and either Internet Addiction or IGD. Many studies considered male gender as a risk factor for internet addiction because of high

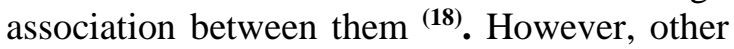
studies showed no specific difference between both genders Reda et al. ${ }^{(19)}$ also Young (20) presented a case of homemaker female who increased her usage of chatting, searching for belonging and emotional support. Such a case would change the schemata of the excessive internet user as a young male theme. This discrepancy between findings of association between gender and Internet Addiction may be related to factors affecting the selected sample e.g. cultural factors and problem awareness ${ }^{(21)}$.

Misuse of the internet has lots of negative consequences e.g. disturbed sleep pattern ${ }^{(20)}$, decreased academic achievement ${ }^{(22)}$, sedentary lifestyle with its side effects ${ }^{(23)}$. In the current study we have tried to test some of the negative effects of misuse of internet.

We tested sleep quality of students using the Pittsburgh Sleep Quality Index (PSQI). A high significant correlation between sleep quality and Internet Addiction (IA) was revealed as we found that $72 \%$ from severe internet addicts were suffering from poor sleep quality. Sleep quality and IA are not only related to each other but also correlated i.e. the more severe the internet addiction, the lesser the sleep quality. Nearly the same results were reported regarding relation between IGD and sleep quality. As we found that $69 \%$ from disordered gamers and $67 \%$ from risky gamers were suffering from poor sleep quality. Also, a high significant correlation between IGD and sleep quality was noticed. Such results agree with other studies which reported that excessive internet use leads to irregular sleep patterns and poor quality of sleep due to an irregular bedtime schedule ${ }^{(24)}$. Also, this could lead to disturbed circadian rhythm ${ }^{(25)}$.

Disturbed sleep pattern, due to late night logins, causes excessive fatigue often making academic or occupational functioning impaired and may decrease one's immune system, leaving the patient vulnerable to diseases ${ }^{(20)}$. In current study, 97.3\% reported losing sleep, either always, often, frequently, occasionally or rarely, due to engaging into online activities ( $25 \%$ from them were "always" doing so). However, some researchers found that not only internet addiction may affect sleep but also people who suffer from decreased ability to fall asleep at night, would engage in internet usage more than others keeping them at higher risk of internet addiction ${ }^{(25)}$.

Although the internet is one of the educational tools, many researchers reported a relation between internet excessive use and decreased academic achievement. For example, Young (26) found that $58 \%$ of those identified as excessive users also received poor grades. Similarly, Shields and Kane ${ }^{(22)}$ found that students' grades were negatively associated with time spent online. In our study, we found that the mean hours students spent online were 5.74 ( \pm SD 3.82). Another study has shown a relationship between problematic Internet use and poor motivation to study, especially in selfgenerated motivational domains ${ }^{(27)}$.

Also, we noticed that the grades of students deteriorate while the severity of IA increases and $98 \%$ from those who failed in exams were internet addicts. Also, a high significant correlation has been found between IGD and students' grades.

\section{Conclusion:}

Internet, the global network, is a double-edged sword. It provides us with lots of information, communication facilities, and many other benefits in work, education, and even leisure time. However, Internet misuse may disrupt different life aspects in the form of family problems, education or academic deterioration, even developmental and physical state may be affected because of the sedentary life and poor care of self.

The current study has revealed a high prevalence rate of Internet Addiction (IA) among Al-Azhar university students. This prevalence was higher than Internet Gaming Disorder (IGD) prevalence. Both of IA and IGD are inversely correlated to sleep quality. Theoretical faculties are at higher risk for IA and IGD. Middle Socioeconomic status (SES) 
of adolescents' parents is related to IA but not related to IGD.

\section{REFERENCES:}

1. Goodman A (1993): Diagnosis and treatment of sexual addiction. Journal of Sex \& Marital Therapy, 19(3): 225-251.

2. Weinstein A, Feder LC, Rosenberg KP et al. (2014): Internet addiction disorder: Overview and controversies. Behavioral Addictions, 5: 99-117.

3. Kuss D, Griffiths MD, Karila L et al. (2014): Internet Addiction: A Systematic Review of Epidemiological Research for the Last Decade, Current Pharmaceutical Design, 20(25): 4026-4052.

4. ITU (2016): Committed to connecting the world [internet]. ITU. Available at: http://www.itu.int.

5. Beard K (2005): Internet addiction: a review of current assessment techniques and potential assessment questions. Cyber Psychology \& Behavior, 8(1): 7 14.

6. Vihang NV (2014): Diagnostic and statistical manual of mental disorders. Indian J Psychiatry, 55(3): 220-223.

7. Chen $Y$ and Gau S (2016): Sleep problems and internet addiction among children and adolescents: a longitudinal study. Journal of Sleep Research, 25(4):458-465.

8. Reda M, Rabie M, Mohsen $\mathbf{N}$ et al. (2012): Problematic internet users and psychiatric morbidity in a sample of Egyptian adolescents. Sci Res., 3(8): p. 626-631.

9. Young KS, Pistner M, O'Mara J et al. (1999): Cyber disorders: The mental health concern for the new millennium. Cyber Psychology and Behavior, 2: 475479.

10. Lemmens JS, Valkenburg PM, Gentile DA (2015): The Internet Gaming Disorder Scale, APA PsycNET, Psychological Assessment, 27(2): 567582.

11. Buysse D, Reynolds C, Monk T et al. (1989): The Pittsburgh sleep quality index: A new instrument for psychiatric practice and research. Psychiatry Research, 28(2):193-213.

12. Krant $R$, Patterson $M$, Lundmark $V$ et al. (1998): Internet Paradox: A social technology that reduces social involvement and psychological wellbeing? American Psychologist, 53: 1017-1031.

13. Cao H, Sun Y, Wan $Y$ et al. (2011): Problematic internet use in Chinese adolescents and its relation to psychosomatic symptoms and life satisfaction, BMC Public Health, 11: 802-5.

14. Soule LC, Shell LW, Kleen BA (2003): Exploring internet addiction: demographic characteristics and stereotypes of heavy internet users. Journal of Computer Information Systems, 44(1): 64-73.

15. Saied SM, El Sabagh HM, El-Afandy AM (2016): Internet and Facebook addiction among Egyptian and Malaysian medical students: a comparative study, Tanta University, Egypt. International Journal of Community Medicine and Public Health, 3(5): 1288-92.

16. Leung $L$ (2014): Predicting Internet risks: a longitudinal panel study of gratifications-sought, internet addiction symptoms, and social media use among children and adolescents. Health Psychology and Behavioral Medicine, 2(1): 424-439.

17. Wu A, Cheung V, Ku L et al. (2013): Psychological risk factors of addiction to social networking sites among Chinese smartphone users, Journal of Behavioral Addictionsm, 2(3): 160-166.

18. Ak S, Koruklu N, Yilmaz Y (2013): A study on Turkish adolescent's internet use: Possible predictors of Internet addiction. Cyber Psychology, Behavior and Social Networking, 16(3):205-9.

19. Reda M, Rabie M, Mohsen $\mathbf{N}$ et al. (2012): Problematic internet users and psychiatric morbidity in a Sample of Egyptian adolescents. Sci Res., 3(8): 626-631. 
20. Young KS (1999): Internet addiction: symptoms, evaluation and treatment. Innovations in clinical practice: A source book. www.scirp.org > reference > ReferencesPapers

21. Kuss D, Griffiths MD, Karila $\mathrm{L}$ et al. (2014): Internet addiction: A systematic review of epidemiological research for the last decade. Current Pharmaceutical Design, 20(25): 4026-4052.

22. Shields N, Kane J (2011): Social and psychological correlates of Internet use among college students. Cyberpsychology. Journal of Psychosocial Research on Cyberspace. https://cyberpsychology.eu/article/view/ 4242/3288

23. Choi YH (2007): Advancement of IT and seriousness of youth Internet addiction, in 2007 International Symposium on the Counseling and Treatment of Youth Internet Addiction.
Seoul, Korea, National Youth Commission, Pp. 20.

24. Kamal NN, Mosallem FA (2013): Determinants of problematic Internet Use among El-Minia highs students in Egypt. International Journal of Preventive Medicine, 4(12):1429-1437.

25. Chen Y, Gau $S$ (2016): Sleep problems and internet addiction among children and adolescents: a longitudinal study. Journal of Sleep Research, 25(4):458465 .

26. Young KS (1998): Caught in the net: how to recognize the signs of internet addiction and a winning strategy for recovery. New York: J. Wiley. Pp. 1-14. https://my.ilstu.edu/ dfgrayb/Personal/i nternet\%20addiction.pdf

27. Reed P, Reay E (2015): Relationship between levels of problematic Internet usage and motivation to study in university students. ERIC., 70(4): 711723. 